\title{
The global prevalence of Toxocara spp. in pediatrics: a systematic review and meta-analysis
}

\begin{abstract}
Behnam Abedi, MSc ${ }^{1}$, Mehran Akbari, MSc ${ }^{2}$, Sahar KhodaShenas, MSc ${ }^{3}$, Alireza Tabibzadeh, MSc ${ }^{4}$, Ali Abedi, MSc $^{5}$, Reza Ghasemikhah, $\mathrm{PhD}^{6}$, Marzieh Soheili, MD ${ }^{7,8}$, Shnoo Bayazidi, $\mathrm{MSc}^{9}$, Yousef Moradi, $\mathrm{PhD}^{10}$

${ }^{1}$ Department of Medical Laboratory, Khomein University of Medical Sciences, Khomein, Iran; ${ }^{2}$ Department of Nursing, Khomein University of Medical Sciences, Khomein, Iran; ${ }^{3}$ Department of Parasitology and Mycology, School of Medicine, Hamadan University of Medical Sciences, Hamadan, Iran; ${ }^{4}$ Departments of Virology, Iran University of Medical Sciences, Tehran, Iran; ${ }^{5}$ Department of Microbiology, Islamic Azad University of Arak, Arak, Iran; ${ }^{6}$ Department of Parasitology and Mycology, School of Medicine, Arak University of Medical Sciences, Arak, Iran; ${ }^{7}$ Faculty of Medicine, Kermanshah University of Medical Sciences, Kermanshah, Iran; ${ }^{8}$ Human Revivification Society of Congress 60, Tehran, Iran; ${ }^{9}$ Department of Epidemiology, School of Public Health, Iran University of Medical Sciences, Tehran, Iran;

${ }^{10}$ Social Determinants of Health Research Center, Research Institute for Health Development, Kurdistan University of Medical Sciences, Sanandaj, Iran
\end{abstract}

Background: Toxocariasis is a zoonotic parasitic disease caused by Toxocara canis and Toxocara cati in humans. Various types of T. canis are important.

Purpose: The current study aimed to investigate the prevalence of Toxocara spp. in pediatrics in the context of a systematic review and meta-analysis.

Methods: The MEDLINE (PubMed), Web of Sciences, Embase, Google Scholar, Scopus, and Cumulative Index of Nursing and Allied Health databases were searched to identify peer-reviewed studies published between January 2000 and December 2019 that report the prevalence of Toxocara spp. in pediatrics. The evaluation of articles based on the inclusion and exclusion criteria was performed by 2 researchers individually.

Results: The results of 31 relevant studies indicated that the prevalence of Toxocara spp. was 3\%-79\% in 10,676 cases. The pooled estimate of global prevalence of Toxocara spp. in pediatrics was 30 (95\% confidence interval, 22\%-37\%; $I^{2}=99.11 \% ; P=0.00$ ). The prevalence was higher in Asian populations than in European, American, and African populations.

Conclusion: Health policymakers should be more attentive to future research and approaches to Toxocara spp. and other zoonotic diseases to improve culture and identify socioeconomically important factors.

Key words: Learning disability, Neurobiology, Reading disability (dyslexia)

\section{Key message}

Is the global prevalence of toxocariasis high among children? The prevalence of toxocariasis is high in pediatric patients. Asian children are more susceptible to the disease than other children. Its virulence varies among different socioeconomic classes in various countries. Hand washing after soil contact, routine pet deworming, and appropriate disposal of pet feces in households with Asian pediatrics are needed to prevent toxocariasis.

\section{Introduction}

Toxocariasis or visceral migraine laryngeal syndrome is a zoonotic parasitic disease caused by Toxocara canis and Toxocara cati in humans. Various types of T. canis in particular can be important. ${ }^{1,2)}$ Each adult worm in the intestines of infected dogs and cats can release a large number of eggs daily through defecation. Toxocariasis is mostly transmitted to humans via water, food, and soil contaminated with eggs. ${ }^{2,3)}$ The eggs of this parasite are opened after entering the human digestive system. The larvae then pass through the intestinal mucosa to the bloodstream and diffuse into organs such as the liver, brain, and eye. Although the larva will be recognized and limited by the immune system forming granuloma, they can survive and persist in this form for up to 11 years. ${ }^{4)}$

The visceral larva migrans (VLM), ocular larvae (OLM), and overt toxocariasis are the most common types of larvae. The clinical symptoms of infection are nonspecific but can include neurological, ocular, pulmonary (asthmatic), dermatological, and rheumatoid arthritis. ${ }^{5)}$ The pathology of this parasite is variable, but it can induce peripheral eosinophilia (20\%-40\%) and fever of unknown origin. The prevalence of parasites varies among geographic regions at rates of 2\%-90\%. ${ }^{6-8)}$

Pediatrics are more susceptible to Toxocara infection since they are more likely to place a contaminated hand or even an egg into their mouth.9) Seroepidemiological evaluations in different countries indicated a global distribution of toxocariasis. Considering the importance of the prevalence of this parasite in the population, this study aimed to evaluate the prevalence of

Corresponding author: Yousef Moradi, PhD, Social Determinants of Health Research Center, Research Institute for Health Development, Kurdistan University of Medical Sciences, Sanandaj, Iran

凶Email: yousefmoradi211@yahoo.com, https://orcid.org/0000-0002-2936-5930

Received: 12 June, 2020, Revised: 22 January, 2021, Accepted: 22 January, 2021

This is an open-access article distributed under the terms of the Creative Commons Attribution Non-Commercial License (http://creativecommons.org/licenses/by-nc/4.0/) which permits unrestricted non-commercial use, distribution, and reproduction in any medium, provided the original work is properly cited.

Copyright (c) 2021 by The Korean Pediatric Society 
toxocariasis in pediatric patients younger than 20 years of age based on a systematic review and meta-analysis of published studies.

\section{Methods}

This study was performed according to the MOOSE (MetaAnalyses of Observational Studies in Epidemiology) and the PRISMA (Preferred Reporting Items for Systematic Reviews and Meta-Analyses). ${ }^{10-12)}$

\section{Search strategy}

In this systematic review, we assessed all original research studies that were relevant to the topic by searching the MEDLINE (PubMed), Web of Sciences, Embase, Google Scholar, Scopus, and Cumulative Index of Nursing and Allied Health databases using keywords such as toxocariasis, Toxocara, Toxocara-antibodies, Pediatrics, Toxocara canis, and Toxocara cati. The search was limited to articles published between January 2000 and December 2019. The researchers searched these databases and manually searched the reference lists and gray literature. Duplicate entries were reviewed by considering the title of published papers, authors, year of publication, and specifications of the source types. In questionable records, the texts were compared. After abstract and title review, some of the articles were eliminated. The retrieved papers were evaluated by 2 researchers (YM, BA) based on the inclusion and exclusion criteria.

\section{Eligibility criteria}

For the current study, the inclusion criteria were publication in the English language and publication between January 2000 and December 2019. The study design and methodologies were cross-sectional. All other studies, such as reviews or metaanalyses, were excluded from the screening. Articles that were conducted on animals were also excluded.

We included all English observational studies published between January 2000 to December 2019 that assessed the prevalence of toxocariasis, therapeutic management, signs, and symptoms in pediatric patients with toxocariasis. Cross-sectional studies were also included. We excluded duplicate non-peerreviewed, review, or meta-analysis articles and papers for which the abstracts and full texts were not available.

\section{Data extraction}

All of the included studies were listed by EndNote software (EndNote X7, Thomson Reuters, Toronto, ON, Canada) and subjected to review and data extraction by 3 independent authors. Two reviewers independently (BA and RGH) extracted the required data from the data contained in the identified articles using a uniform Excel sheet. Discrepancies in the extracted data were resolved through consensus. If agreement could not be reached, it was resolved by referral to a third investigator (YM). For the current study, the data extraction section contained the first author's name, year of publication, study location, study type, sample size, age, positive population prevalence, and method of detecting the infection.

\section{Risk of bias}

The quality of all studies was assessed by 2 independent authors using the Modified Newcastle-Ottawa Scale for crosssectional studies. ${ }^{13)}$

\section{Statistical analysis}

We used a random-effects model to generate a pooled prevalence presented as percentage and $95 \%$ confidence interval (CI) with Metaprop order. Interstudy heterogeneity was assessed using the $I^{2}$ heterogeneity statistic reported as a percentage (\%) to determine the extent of interstudy variation. A forest plot was used to present the meta-analysis results schematically. Egger test and a funnel plot were applied to evaluate the presence of

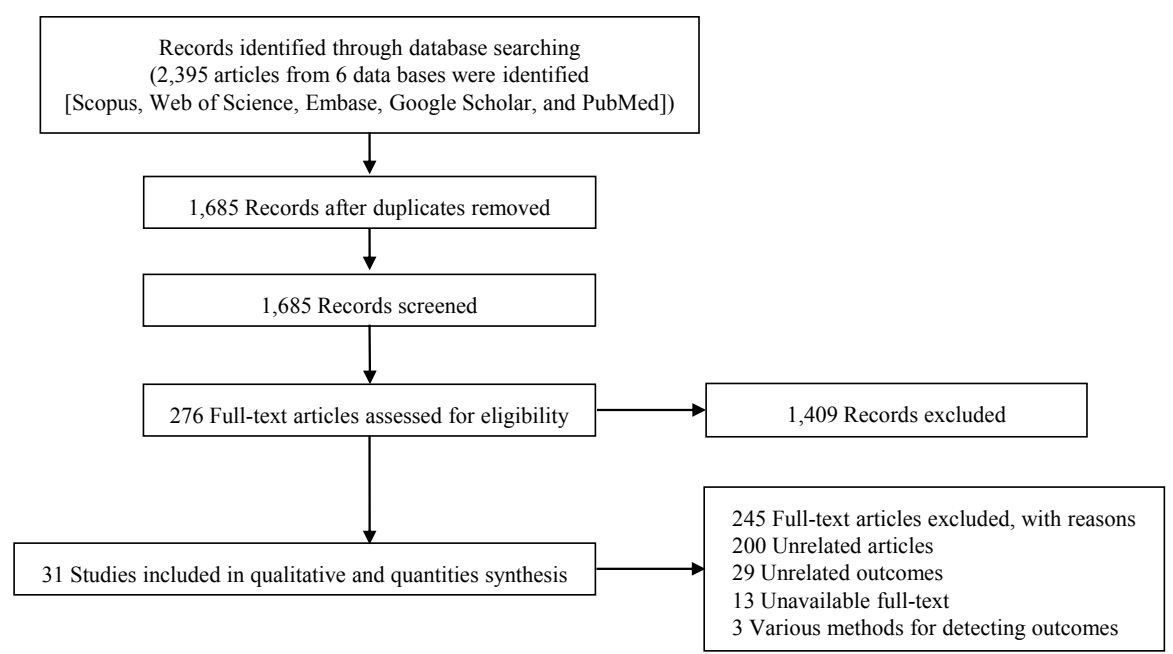

Fig. 1. Preferred Reporting Items for Systematic Reviews and Meta-Analyses diagram and search strategy results. 
publication bias. In addition, a subgroup analysis was performed to identify different sources of heterogeneity. The statistical analysis was performed using STATA 15.0 (Stata Corp., College Station, TX, USA), and statistical significance was set at $P<0.05$.

\section{Results}

The conducted search retrieved 2,395 studies. After duplicate removal and title and abstract screening, 276 relevant studies remained. The search and screening results are illustrated in Fig. 1. The assessment of 31 studies revealed that the prevalence of Toxocara was $3 \%-79 \%$ in 10,676 cases. Of the total number of children (10,676), 3,525 had Toxocara infection (Table 1). In addition, most of the conducted studies used enzymelinked immunosorbent assay (ELISA) to diagnose the infection. Furthermore, in most of the mentioned studies, the patients were younger than 12 years of age. The results from the different included studies are listed in Table 1.

The results demonstrated that the pooled prevalence of
Toxocara in pediatric patients worldwide was 30 (95\% CI, 22\%$37 \% ; I^{2}=99.11 \% ; P=0.00$ ) (Fig. 2), but since the CI of Egger test did not include zero, a significant bias occurred in the publication of the results (coefficient $=11.58 ; \mathrm{T}=4.39 ; P=0.001 ; 95 \% \mathrm{CI}$, 6.23-16.93). The funnel plot is shown in Fig. 3.

The subgroup analysis by continent showed that the pooled prevalence of Toxocara in pediatric patients in Asia, America, Africa, and Europe was 35\% (95\% CI, 3\%-67\%; $I^{2}=99.43 \%$; $P=0.00)$, 31\% (95\% CI, 22\%-40\%; $I^{2}=99.01 \% ; P=0.00$ ), $21 \%$ (95\% CI, $\left.1 \%-52 \% ; I^{2}=98.75 \% ; P=0.00\right)$, and $26 \%(95 \%$ CI, 19\%-34\%; $I^{2}=85.94 \% ; P=0.00$ ), respectively (Table 2 and Fig. 4).

\section{Meta-regression analysis}

We used a meta-regression analysis to assess the effect of suspected variables such as year of study and sample size on heterogeneity. The results of the meta-regression analysis shown in Table 2 did not show any significant association between this variable and the prevalence of Toxocara spp. in pediatric patients (Table 3 and Fig. 5).

Table 1. Studies examining the prevalence of Toxocara spp. in pediatric patients

\begin{tabular}{|c|c|c|c|c|c|c|c|c|c|}
\hline Study & Country & Year & Sample size (n) & Age range (yr) & Specimen & Study design & Prevalence (\%) & Methods & NOS score \\
\hline Sadjjadi et al. ${ }^{21)}$ & Iran & 2000 & 519 & $6-13$ & Serum & CS & 51.30 & ELISA & 6 \\
\hline Alonso et al. ${ }^{33)}$ & Brazil & 2000 & 206 & $1-14$ & Serum & CS & 37.9 & SLISA & 7 \\
\hline Aguiar-Santos et al. ${ }^{34)}$ & Brazil & 2004 & 386 & $0-18$ & Serum & CS & 39.4 & ELISA & 7 \\
\hline Muradian et al. ${ }^{35)}$ & Brazil & 2005 & 338 & $1-15$ & Serum & CS & 79.40 & ELISA & 7 \\
\hline Paludo et al. ${ }^{36)}$ & Brazil & 2007 & 450 & $1-12$ & Serum & CS & 28.8 & ELISA & 7 \\
\hline Nourian et al. ${ }^{37)}$ & Iran & 2008 & 810 & $1-2$ & Serum & CS & 2.7 & ELISA & 6 \\
\hline Espinoza et al. ${ }^{38)}$ & Peru & 2008 & 182 & $6-12$ & Serum & CS & 32.5 & ELISA & 6 \\
\hline Zarnowska et al. ${ }^{39)}$ & Poland & 2008 & 343 & - & Serum & CS & 24.70 & ELISA & 6 \\
\hline Dar et al. ${ }^{40)}$ & India & 2008 & 110 & $5-16$ & Serum & CS & 32.7 & ELISA & 6 \\
\hline Antonios et al. ${ }^{41)}$ & Egypt & 2008 & 128 & $1-12$ & Serum & $\mathrm{CS}$ & 6 & ELISA & 6 \\
\hline Alavi et al. ${ }^{42)}$ & Iran & 2008 & 29 & $6-15$ & Serum & CS & 55 & ELISA & 7 \\
\hline Sviben et al. ${ }^{43)}$ & Croatia & 2009 & 142 & $3-18$ & Serum & CS & 43 & ELISA & 7 \\
\hline Yazar et al. ${ }^{44)}$ & Turkey & 2010 & 112 & - & Stool & CS & 21.4 & ELISA & 6 \\
\hline Santar m et al. ${ }^{45)}$ & Brazil & 2011 & 252 & $1-15$ & Serum & $\mathrm{CS}$ & 11.10 & ELISA & 6 \\
\hline Mattia et al. ${ }^{46)}$ & Brazil & 2012 & 353 & $0-12$ & Serum & CS & 36.8 & ELISA & 8 \\
\hline Manini et al. ${ }^{9}$ & Brazil & 2012 & 90 & $1-12$ & Serum & CS & 17.80 & ELISA & 7 \\
\hline Sariego et al. ${ }^{47)}$ & Cuban & 2012 & 1,011 & $5-14$ & Serum & CS & 38.80 & ELISA & 6 \\
\hline Schoenardie et al. ${ }^{48)}$ & Brazil & 2013 & 427 & $1-12$ & Serum & CS & 50.60 & ELISA & 6 \\
\hline Kanobana et al. ${ }^{49)}$ & Cuban & 2013 & 958 & $5-14$ & Serum & CS & 40 & ELISA & 6 \\
\hline Guilherme et al. ${ }^{50)}$ & Brazil & 2013 & 167 & $0-15$ & Serum & CS & 4.2 & ELISA & 7 \\
\hline Pautova et al. ${ }^{51)}$ & Russia & 2013 & 144 & $1-17$ & Serum & CS & 18.8 & ELISA & 8 \\
\hline Mendon a et al. ${ }^{52)}$ & Brazil & 2013 & 1,309 & 4-11 & Serum & CS & 48.4 & ELISA & 7 \\
\hline Oliart-Guzm n et al. ${ }^{53)}$ & Brazil & 2014 & 539 & $6 m-69 m$ & Serum & CS & $23-28$ & ELISA & 7 \\
\hline Archelli et al. ${ }^{54)}$ & Spain & 2014 & 120 & $0-3$ & Serum & CS & 38.3 & ELISA & 7 \\
\hline Marchioro et al. ${ }^{55)}$ & Brazil & 2015 & 554 & $1-12$ & Serum & CS & 7.4 & ELISA & 7 \\
\hline Mart nez et al. ${ }^{56)}$ & Venezuela & 2015 & 224 & $1-6$ & Serum & CS & 29 & ELISA & 7 \\
\hline Cort s et al. ${ }^{57)}$ & Mexico & 2015 & 183 & $3-16$ & Serum & CS & 12 & ELISA & 7 \\
\hline Mazur-Melewska et al. ${ }^{23)}$ & Poland & 2016 & 42 & $1-18$ & Serum & CS & 30.3 & ELISA & 6 \\
\hline Gabrielli et al. ${ }^{57)}$ & Serbia & 2017 & 40 & $2-14$ & Serum & CS & 10 & ELISA/WB & 7 \\
\hline Sowemimo et al. ${ }^{58)}$ & Nigeria & 2017 & 308 & $0-5$ & Serum & CS & 37 & WB & 7 \\
\hline Fialho et al. ${ }^{59)}$ & Brazil & 2017 & 200 & $1-12$ & Serum & CS & 16 & ELISA & 7 \\
\hline
\end{tabular}

NOS, Newcastle-Ottawa scale; CS, cross-sectional; ELISA, enzyme-linked immunosorbent assay; CE, cryptogenic epilepsy; WB, Western blot. 


\begin{tabular}{|c|c|c|c|}
\hline Study & & $\begin{array}{c}\text { Prevalence } \\
\text { with } 95 \% \mathrm{CI}\end{array}$ & $\begin{array}{c}\text { Weight } \\
(\%)\end{array}$ \\
\hline Sadjjadi, 2000 & 불 & $0.51[0.47,0.56]$ & 3.29 \\
\hline Alonso, 2000 & 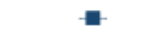 & $0.38[0.31,0.45]$ & 3.22 \\
\hline Aguiar-Santos, 2004 & 불 & $0.39[0.35,0.44]$ & 3.28 \\
\hline Muradian, 2005 & & $0.79[0.75,0.84]$ & 3.29 \\
\hline Paludo, 2007 & $=$ & $0.29[0.25,0.33]$ & 3.30 \\
\hline Nourian, 2008 & $\mathbf{n}$ & $0.03[0.02,0.04]$ & 3.34 \\
\hline Espinoza, 2008 & $=$ & $0.33[0.26,0.39]$ & 3.22 \\
\hline Żarnowska, 2008 & $=$ & $0.25[0.20,0.29]$ & 3.29 \\
\hline Dar, 2008 & - & $0.33[0.24,0.41]$ & 3.14 \\
\hline Antonios, 2008 & $=$ & $0.06[0.02,0.10]$ & 3.30 \\
\hline Alavi, 2008 & 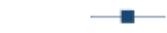 & $0.55[0.37,0.73]$ & 2.60 \\
\hline Sviben, 2009 & - & $0.43[0.35,0.51]$ & 3.16 \\
\hline Yazar, 2010 & - & $0.21[0.14,0.29]$ & 3.19 \\
\hline Santarém, 2011 & $=$ & $0.11[0.07,0.15]$ & 3.30 \\
\hline Mattia, 2012 & 불 & $0.37[0.32,0.42]$ & 3.28 \\
\hline Manini, 2012 & - & $0.18[0.10,0.26]$ & 3.17 \\
\hline Sariego, 2012 & a & $0.39[0.36,0.42]$ & 3.32 \\
\hline Schoenardie, 2013 & 불 & $0.51[0.46,0.55]$ & 3.28 \\
\hline Kanobana, 2013 & $\mathbf{n}$ & $0.40[0.37,0.43]$ & 3.32 \\
\hline Guilherme, 2013 & $\mathbf{a}$ & $0.04[0.01,0.07]$ & 3.32 \\
\hline Pautova, 2013 & - & $0.19[0.12,0.25]$ & 3.23 \\
\hline Mendonça, 2013 & $\mathbf{a}$ & $0.48[0.46,0.51]$ & 3.33 \\
\hline Oliart-Guzmán, 2014 & = & $0.28[0.24,0.32]$ & 3.31 \\
\hline Archelli, 2014 & - & $0.38[0.30,0.47]$ & 3.14 \\
\hline Marchioro, 2015 & $\mathbf{n}$ & $0.07[0.05,0.10]$ & 3.33 \\
\hline Martinez, 2015 & $=$ & $0.29[0.23,0.35]$ & 3.25 \\
\hline Cortés, 2015 & 둘 & $0.12[0.07,0.17]$ & 3.28 \\
\hline Mazur-Melewska, 2016 & - & $0.30[0.16,0.44]$ & 2.86 \\
\hline Gabrielli, 2017 & - & $0.10[0.01,0.19]$ & 3.11 \\
\hline Sowemimo, 2017 & $=$ & $0.37[0.32,0.42]$ & 3.26 \\
\hline Fialho, 2017 & $=$ & $0.16[0.11,0.21]$ & 3.27 \\
\hline Overall & - & $0.30[0.24,0.36]$ & \\
\hline \multicolumn{4}{|l|}{ Heterogeneity: $\tau^{2}=0.03, \mathrm{I}^{2}=98.69 \%, \mathrm{H}^{2}=76.06$} \\
\hline \multicolumn{4}{|l|}{ Test of $\theta_{1}=\theta_{1}: Q(30)=3364.28, p=0.00$} \\
\hline \multicolumn{4}{|l|}{ Test of $\theta=0: z=9.47, p=0.00$} \\
\hline & $\begin{array}{llll}0 & .2 & 4 & .6\end{array}$ & 8 & \\
\hline
\end{tabular}

Fig. 2. Meta-analysis of the global prevalence of Toxocara spp. in pediatric patients.

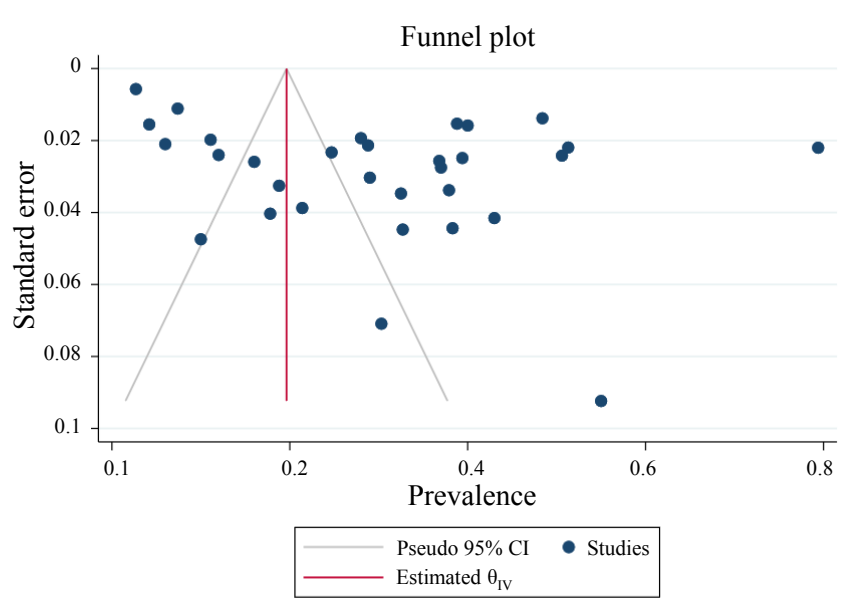

Fig. 3. Publication bias of the prevalence of Toxocara spp. in pediatric patients. $\mathrm{Cl}$, confidence interval.

\section{Discussion}

Toxocara is a worldwide worm and common intestinal parasite for cats and dogs that have the ability to infect humans. ${ }^{14)}$ Toxocara can be responsible for a variety of clinical manifestations. ${ }^{14)}$ The worm's eggs can pass through the feces of animals and preserve infectivity for a long time in the soil. ${ }^{14)}$ Soil contamination with Toxoplasma is more frequent in humans. ${ }^{15)}$
Table 2. Pooled prevalence of Toxocara spp. in pediatric patients by continent

\begin{tabular}{|c|c|c|c|c|c|c|}
\hline \multirow{2}{*}{ Continents } & \multirow{2}{*}{$\begin{array}{c}\text { Prevalence } \\
(95 \% \mathrm{Cl})\end{array}$} & \multicolumn{3}{|c|}{$\begin{array}{c}\text { Between } \\
\text { studies }\end{array}$} & \multicolumn{2}{|c|}{$\begin{array}{l}\text { Between } \\
\text { subgroups }\end{array}$} \\
\hline & & $P^{2}$ & $Q$ & $\begin{array}{c}\text { Phetero- } \\
\text { geneity }\end{array}$ & $Q$ & $\begin{array}{c}\text { Phetero- } \\
\text { geneity }\end{array}$ \\
\hline Africa & $21 \%(1-52)$ & $98.75 \%$ & 80.25 & 0.001 & \multirow{4}{*}{1.01} & \multirow{4}{*}{0.80} \\
\hline American & $31 \%(22-40)$ & $98.83 \%$ & 172.82 & 0.001 & & \\
\hline Asian & $35 \%(11-58)$ & $98.95 \%$ & 523.25 & 0.081 & & \\
\hline European & $21 \%(1-52)$ & $88.45 \%$ & 42.67 & 0.001 & & \\
\hline
\end{tabular}

$\mathrm{Cl}$, confidence interval.

It can be concluded that in some cases, closer contact with animals can increase the exposure risk for this parasite. ${ }^{916)}$ The current study aimed to systematically review the prevalence of Toxocara infection in pediatric patients. The results of 31 relevant studies indicated that the global prevalence of Toxocara in pediatric patients was $30\left(95 \% \mathrm{CI}, 22 \%-37 \% ; I^{2}=99.11 \%\right.$; $P=0.00$ ). The prevalence may vary among sample populations and geographical regions.

Oliart-Guzmán et al. ${ }^{17)}$ investigated the seroprevalence of Toxocara in households with children in Western Brazilian Amazon over 7 years. They concluded that the prevalence of infection in pediatric patients less than 5 years of age was $28 \%$, $23.3 \%$, and $13.9 \%$ in 2003,2010 , and 2011, respectively. Oliart-Guzmán et al. ${ }^{17)}$ suggested that water quality and the treatment of infected animals can be an appropriate strategy for preventing infection in these patients. Roldan et al. ${ }^{18)}$ investigated eosinophilia and other risk factors of Toxocara infection. They used 2 groups of seropositive and seronegative pediatrics. Their results showed that a dry cough and eosinophilia are significantly associated with Toxocara infection. ${ }^{17)}$

Serologic techniques are reliable methods that can detect larval antiantigens. The most commonly used serologic test is ELISA testing, which applies the secretion antigens of the parasite larvae. ${ }^{2)}$ Seroepidemiological evaluations in different countries have shown a global distribution of toxocariasis. The prevalence in American pediatrics is 4.6\%-7.3\% in the USA, $2.5 \%$ in Germany, and $19 \%$ in the Netherlands. ${ }^{19)}$ In Iran, the prevalence among school children was $25.6 \%$ in Shiraz and 31\% in Ilam. ${ }^{20,21)}$ Musso et al. ${ }^{22)}$ reported the association of viral and bacterial central nervous system infections in pediatrics with Toxocara by evaluating the serum and cerebrospinal fluid of 381 patients. Toxocara immunoglobulin $\mathrm{G}(\mathrm{IgG})$ was present in $32 \%$ of meningitis and $34 \%$ of control group patients, a difference that was not statistically significant.

As mentioned above, Toxocara can have a variety of clinical manifestations. ${ }^{14)}$ Mazur-Melewska et al. ${ }^{23)}$ evaluated the pulmonary presentation of Toxocara in 119 positive patients who were 1-19 years of age. Their results suggested that high levels of eosinophilia and hyperimmunoglobulinemia $\mathrm{E}$ could be related to Toxocara infection. In addition, Pinelli et al. ${ }^{24}$ assessed Toxocara infection in patients with suspected VLM and OLM from 1998 to 2009. Their results indicated a significantly 


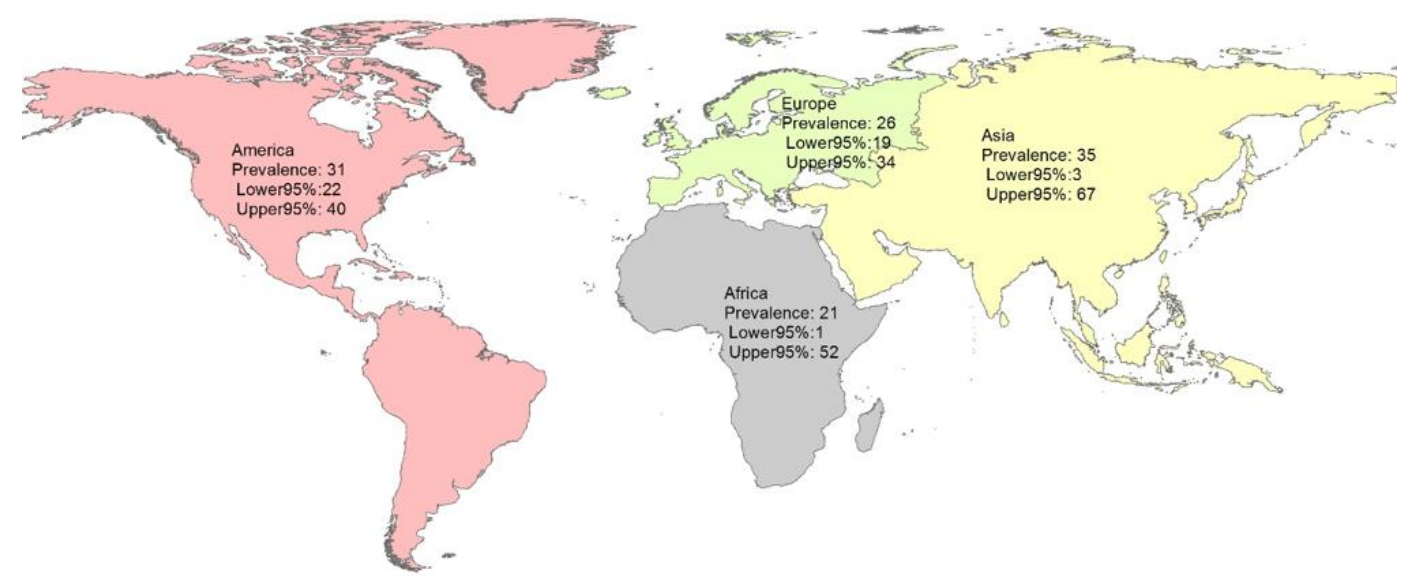

Fig. 4. Global prevalence (\%) of Toxocara spp. in pediatric patients by continent.

Table 3. Meta-regression analysis to assess the effect of suspected variables on the pooled prevalence of Toxocara spp. in pediatric patients

\begin{tabular}{|c|c|c|c|c|c|c|}
\hline \multirow{2}{*}{ Prevalence } & \multicolumn{3}{|c|}{ Univariable model } & \multicolumn{3}{|c|}{ Multivariable model } \\
\hline & $\beta$ & SE & $P$ value $(95 \% \mathrm{Cl})$ & $\beta$ & SE & $P$ value $(95 \% \mathrm{Cl})$ \\
\hline \multicolumn{7}{|c|}{ Toxocara spp. in the pediatrics } \\
\hline Sample size & 0.001 & 0.0003 & $0.388(-0.001$ to 0.003$)$ & 0.002 & 0.003 & $0.370(-0.001$ to 0.003$)$ \\
\hline Years of published & -0.013 & 0.008 & $0.084(-0.001$ to 0.003$)$ & -0.014 & 0.008 & $0.094(-0.300$ to 0.002$)$ \\
\hline
\end{tabular}

$\mathrm{SE}$, standard error; $\mathrm{Cl}$, confidence interval.
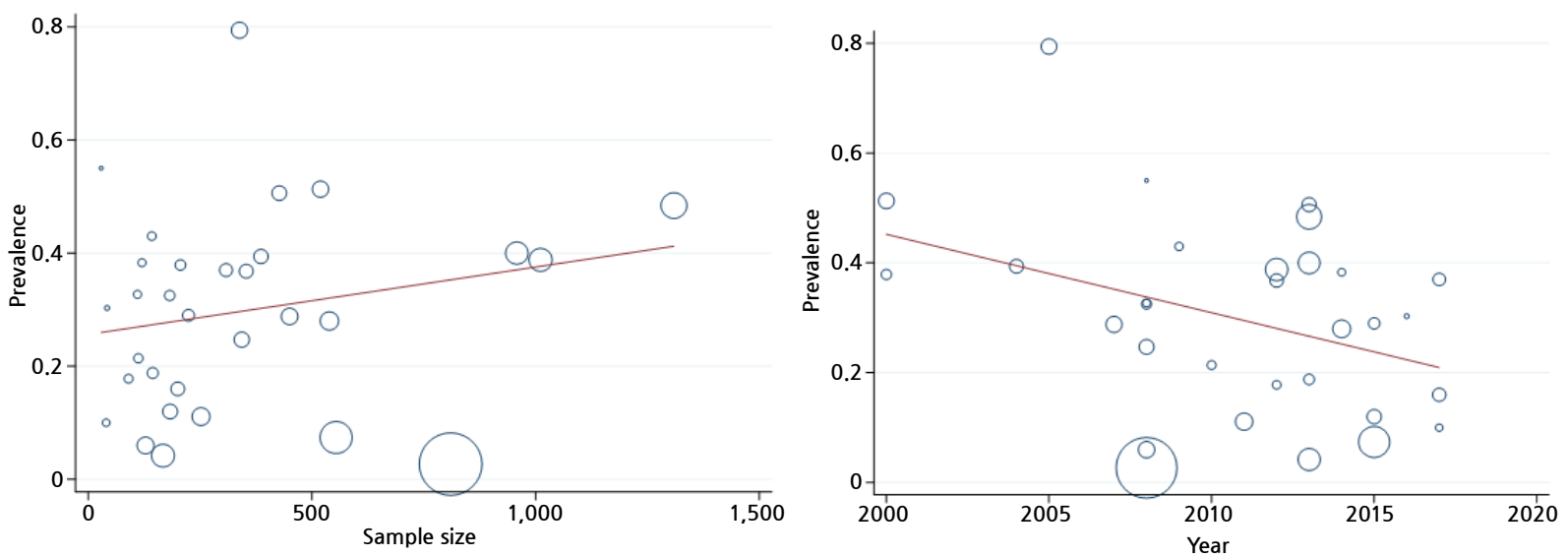

Fig. 5. Meta-regression graph of the prevalence of Toxocara spp. in pediatric patients by sample size and publication year.

decreased rate of infection in the Netherlands that has increased over time as the children grew up.

Epilepsy is a neurological disorder that leads to epileptic seizures. $^{25,26)}$ Epilepsy can be idiopathic or due to trauma, hypoxia, or infection. ${ }^{27,28)}$ El-Tantawy et al. ${ }^{29)}$ assessed Toxocara infection in cryptogenic epilepsy patients. The etiology was unknown in these patients, but brain diseases are mostly suspected. Anti-Toxocara IgG was found in $48 \%$ of the cryptogenic epilepsy patients and 46 of the controls, but the difference was not statistically significant. ${ }^{29,30)}$

Sharghi et al. ${ }^{31)}$ investigated Toxocara infection as a risk factor for asthma in 95 patients aged $2-15$ years and 229 controls. The result showed no statistically significant association between Toxocara and asthma, but Toxocara prevalence showed a significantly higher rate in Hispanic children of Puerto Rican descent. It can be concluded that this race is more susceptible to the disease. In addition, Silva et al. ${ }^{32)}$ reported the prevalence of Toxocara as a risk factor for atopia and asthma. They reported that the prevalence in northern Brazil is 63\% in 791 patients and there is an association between Toxocara infection and serum IgE causing cross-reaction and atopia.

These results show a 35\% prevalence of Toxocara infection in Asian pediatrics, a rate that is higher than that in other continents. We assume that the factors responsible for this variation likely represent differences in public health and sanitation status, cultural and social conditions, environmental hygiene, and climate. ${ }^{31,32)}$ This was a comprehensive meta-analysis of 31 valid publications evaluating 10,676 pediatrics on this topic. Most of 
the evaluated studies had an appropriate study population. The possibility that some patients were included in more than one report was low. The number of case reports in our assay was low, which leads to a lower risk of publication bias and increases the level of evidence of our findings. The limitations of this study are its high heterogeneity in the pooled estimate, differences in the diagnostic methods, and study population in primary studies.

According to this systematic review and meta-analysis, the global prevalence of Toxocara in pediatrics varies widely among geographical regions. The prevalence of Toxocara in Asian pediatrics was higher than those in other continents, which shows that in this country and in other continents, health policymakers should be more focused on future research and approaches related to Toxocara and other zoonotic diseases, improve the culture, and identify socioeconomically important factors.

\section{Footnotes}

Conflicts of interest: No potential conflict of interest relevant to this article was reported.

\section{ORCID:}

Behnam Abedi 10 https://orcid.org/0000-0002-9016-8952

Mehran Akbari $\odot$ https://orcid.org/0000-0002-1699-1051

Sahar KkodaShenas (1) https://orcid.org/0000-0002-1801-9119

Alireza Tabibzadeh 1 https://orcid.org/0000-0003-0070-2208

Ali Abedi 1 https://orcid.org/0000-0002-0019-1623

Reza Ghasemikhah 10 https://orcid.org/0000-0002-9677-7484

Marzieh Soheili $\odot$ https://orcid.org/0000-0002-1170-2839

Shnoo Bayazidi ㄴ https://orcid.org/0000-0001-6167-3688

Yousef Moradi $\odot$ https://orcid.org/0000-0002-2936-5930

\section{References}

1. Macpherson $\mathrm{CN}$. The epidemiology and public health importance of toxocariasis: a zoonosis of global importance. Int J Parasitol 2013;43:9991008.

2. Magnaval JF, Glickman LT, Dorchies P, Morassin B. Highlights of human toxocariasis. Korean J Parasitol 2001;39:1-11.

3. Schacher JF. A contribution to the life history and larval morphology of Toxocara canis. J Parasitol 1957;43:599-610 passim.

4. Degouy A, Menat C, Aubin F, Piarroux R, Woronoff-Lemsi MC, Humbert P. La toxocarose Toxocariasis. Presse Med 2001;30(39-40 Pt 1):1933-8.

5. Sharma R, Singh BB, Gill JP. Larva migrans in India: veterinary and public health perspectives. J Parasit Dis 2015;39:604-12.

6. Buijs J, Borsboom G, van Gemund JJ, Hazebroek A, van Dongen PA, van Knapen F, et al. Toxocara seroprevalence in 5 -year-old elementary schoolchildren: relation with allergic asthma. Am J Epidemiol 1994;140: 839-47.

7. Genchi C, Di Sacco B, Gatti S, Sangalli G, Scaglia M. Epidemiology of human toxocariasis in northern Italy. Parassitologia 1990;32:313-9.

8. MacLean JD, Graeme-Cook FM. Case records of the Massachusetts General Hospital. Weekly clinicopathological exercises. Case 12-2002. A 50 -year-old man with eosinophilia and fluctuating hepatic lesions. N Engl
JMed 2002;346:1232-9.

9. Manini MP, Marchioro AA, Colli CM, Nishi L, Falavigna-Guilherme AL. Association between contamination of public squares and seropositivity for Toxocara spp. in children. Vet Parasitol 2012;188:48-52.

10. Vandenbroucke JP, von Elm E, Altman DG, Gøtzsche PC, Mulrow CD, Pocock SJ, et al. Strengthening the Reporting of Observational Studies in Epidemiology (STROBE): explanation and elaboration. PLoS Med 2007;4:e297.

11. von Elm E, Altman DG, Egger M, Pocock SJ, Gøtzsche PC, Vandenbroucke JP, et al. The Strengthening the Reporting of Observational Studies in Epidemiology (STROBE) statement: guidelines for reporting observational studies. Ann Intern Med 2007;147:573-7.

12. Moher D, Liberati A, Tetzlaff J, Altman DG; PRISMA Group. Preferred reporting items for systematic reviews and meta-analyses: the PRISMA statement. PLoS Med 2009;6:e1000097.

13. Peterson J, Welch V, Losos M, Tugwell P. The Newcastle-Ottawa scale (NOS) for assessing the quality of nonrandomised studies in metaanalyses. Ottawa: Ottawa Hospital Research Institute, 2011.

14. Thullier P, Guglielmo V, Rajerison M, Chanteau S. Short report: Serodiagnosis of plague in humans and rats using a rapid test. Am J Trop Med Hyg 2003;69:450-1.

15. Won KY, Kruszon-Moran D, Schantz PM, Jones JL. National seroprevalence and risk factors for Zoonotic Toxocara spp. infection. Am J Trop Med Hyg 2008;79:552-7.

16. Gennari SM, Kasai N, de Jesus Pena HF, Cortez A. Ocorrência de protozoários e helmintos em amostras de fezes de cães e gatos da cidade de São Paulo. Braz J Vet Res Anim Sci 1999;36:87-91.

17. Oliart-Guzmán H, Delfino BM, Martins AC, Mantovani SA, Braña AM, Pereira TM, et al. Epidemiology and control of child toxocariasis in the western Brazilian Amazon - a population-based study. Am J Trop Med Hyg 2014;90:670-81.

18. Roldán WH, Espinoza YA, Atúncar A, Ortega E, Martinez A, Saravia $\mathrm{M}$. Frequency of eosinophilia and risk factors and their association with Toxocara infection in schoolchildren during a health survey in the north of Lima, Peru. Rev Inst Med Trop Sao Paulo 2008;50:273-8.

19. Overgaauw PA. Aspects of Toxocara epidemiology: human toxocarosis. Crit Rev Microbiol 1997;23:215-31.

20. Sadjjadi SM, Khosravi M, Mehrabani D, Orya A. Seroprevalence of toxocara infection in school children in Shiraz, southern Iran. J Trop Pediatr 2000;46:327-30.

21. Shokouhi S, Abdi J. Seroprevalence of Toxocara in children from urban and rural areas of Ilam Province, West Iran. Osong Public Health Res Perspect 2018;9:101-4.

22. Musso C, Lemos EM, Tsanaclis AM, Pereira FE. Toxocara infection is not associated with viral or bacterial central nervous system infection in children. Neuropediatrics 2006;37:126-9.

23. Mazur-Melewska K, Jończyk-Potoczna K, Kemnitz P, Mania A, Figlerowicz M, Służewski W. Pulmonary presentation of Toxocara sp. infection in children. Pneumonol Alergol Pol 2015;83:250-5.

24. Pinelli E, Herremans T, Harms MG, Hoek D, Kortbeek LM. Toxocara and Ascaris seropositivity among patients suspected of visceral and ocular larva migrans in the Netherlands: trends from 1998 to 2009. Eur J Clin Microbiol Infect Dis 2011;30:873-9.

25. Fisher RS, Acevedo C, Arzimanoglou A, Bogacz A, Cross JH, Elger CE, et al. ILAE official report: a practical clinical definition of epilepsy. Epilepsia 2014;55:475-82.

26. Chang BS, Lowenstein DH. Epilepsy. N Engl J Med 2003;349:1257-66.

27. Fisher RS, van Emde Boas W, Blume W, Elger C, Genton P, Lee P, et al. Epileptic seizures and epilepsy: definitions proposed by the International League Against Epilepsy (ILAE) and the International Bureau for Epilepsy (IBE). Epilepsia 2005;46:470-2.

28. Hauser WA, Kurland LT. The epidemiology of epilepsy in Rochester, Minnesota, 1935 through 1967. Epilepsia 1975;16:1-66.

29. El-Tantawy NL, El-Nahas HA, Salem DAB, Salem NAB, Hasaneen BM. Seroprevalence of Toxoplasma gondii and Toxocara spp. in children with cryptogenic epilepsy. Am J Infect Dis Microbiol 2013;1:92-5.

30. Rostami A, Sepidarkish M, Ma G, Wang T, Ebrahimi M, Fakhri Y, 
et al. Global prevalence of Toxocara infection in cats. Adv Parasitol 2020;109:615-39.

31. Sharghi N, Schantz PM, Caramico L, Ballas K, Teague BA, Hotez PJ. Environmental exposure to Toxocara as a possible risk factor for asthma: a clinic-based case-control study. Clin Infect Dis 2001;32:E111-6.

32. Silva MB, Amor ALM, Santos LN, Galvão AA, Oviedo Vera AV, Silva ES, et al. Risk factors for Toxocara spp. seroprevalence and its association with atopy and asthma phenotypes in school-age children in a small town and semi-rural areas of Northeast Brazil. Acta Trop 2017;174:158-64.

33. Alonso JM, Bojanich MV, Chamorro M, Gorodner JO. Toxocara seroprevalence in children from a subtropical city in Argentina. Rev Inst Med Trop Sao Paulo 2000;42:235-7.

34. Aguiar-Santos AM, Andrade LD, Medeiros Z, Chieffi PP, Lescano SZ, Perez EP. Human toxocariasis: frequency of anti-Toxocara antibodies in children and adolescents from an outpatient clinic for lymphatic filariasis in Recife, Northeast Brazil. Rev Inst Med Trop Sao Paulo 2004;46:81-5.

35. Muradian V, Gennari SM, Glickman LT, Pinheiro SR. Epidemiological aspects of Visceral Larva Migrans in children living at São Remo Community, São Paulo (SP), Brazil. Vet Parasitol 2005;134:93-7.

36. Paludo ML, Falavigna DL, Elefant GR, Gomes ML, Baggio ML, Amadei LB, et al. Frequency of Toxocara infection in children attended by the health public service of Maringá, south Brazil. Rev Inst Med Trop Sao Paulo 2007;49:343-8.

37. Nourian AA, Amiri M, Ataeian A, Haniloo A, Mosavinasab SN, Badali H. Seroepidemiological study for toxocariasis among children in Zanjannorthwest of Iran. Pak J Biol Sci 2008;11:1844-7.

38. Espinoza YA, Huapaya PH, Roldán WH, Jiménez S, Arce Z, Lopez E. Clinical and serological evidence of Toxocara infection in school children from Morrope district, Lambayeque, Peru. Rev Inst Med Trop Sao Paulo 2008;50:101-5.

39. Zarnowska H, Borecka A, Gawor J, Marczyńska M, Dobosz S, Basiak W. A serological and epidemiological evaluation of risk factors for toxocariasis in children in central Poland. J Helminthol 2008;82:123-7.

40. Dar ZA, Tanveer S, Yattoo GN, Sofi BA, Dar PA, Wani SA. Presence of anti-Toxocara antibodies in children population of district Anantnag and Pulwama of Kashmir valley. Indian J Med Microbiol 2008;26:400-2

41. Antonios SN, Eid MM, Khalifa EA, Othman AA. Seroprevalence study of Toxocara canis in selected Egyptian patients. J Egypt Soc Parasitol 2008;38:313-8.

42. Alavi SM, Sefidgaran G. Frequency of anti Toxocara antibodies in schoolchildren with chronic cough and eosinophilia in Ahwaz, Iran, 2006. Pak J Med Sci 2008;24:360-3.

43. Sviben M, Cavlek TV, Missoni EM, Galinović GM. Seroprevalence of Toxocara canis infection among asymptomatic children with eosinophilia in Croatia. J Helminthol 2009;83:369-71.

44. Yazar S, Yaman O, Cetinkaya U, Hamamci B, Sahin I. Investigation of anti-Toxocara canis IgG antibodies in patients presenting at The Erciyes University Medical Faculty, Department of Parasitology. Turkiye Parazitol Derg 2010;34:24-6.

45. Santarém VA, Leli FN, Rubinsky-Elefant G, Giuffrida R. Protective and risk factors for toxocariasis in children from two different social classes of Brazil. Rev Inst Med Trop Sao Paulo 2011;53:66-72.

46. Mattia S, Colli CM, Adami CM, Guilherme GF, Nishi L, RubinskyElefant $G$, et al. Seroprevalence of Toxocara infection in children and environmental contamination of urban areas in Paraná State, Brazil. J Helminthol 2012;86:440-5.

47. Sariego I, Kanobana K, Junco R, Vereecken K, Núñez FA, Polman K, et al. Frequency of antibodies to Toxocara in Cuban schoolchildren. Trop Med Int Health 2012;17:711-4.

48. Schoenardie ER, Scaini CJ, Brod CS, Pepe MS, Villela MM, McBride AJ, et al. Seroprevalence of Toxocara infection in children from southern Brazil. J Parasitol 2013;99:537-9.

49. Kanobana K, Vereecken K, Junco Diaz R, Sariego I, Rojas L, Bonet Gorbea M, et al. Toxocara seropositivity, atopy and asthma: a study in Cuban schoolchildren. Trop Med Int Health 2013;18:403-6.

50. Guilherme EV, Marchioro AA, Araujo SM, Falavigna DL, Adami C, Falavigna-Guilherme G, et al. Toxocariasis in children attending a Public Health Service Pneumology Unit in Paraná State, Brazil. Rev Inst Med Trop Sao Paulo 2013;55:S0036-46652013000300189.

51. Pautova EA, Dovgalev AS, Astanina SIu. Toxocariasis in children and adolescents with allergic and bronchopulmonary diseases, HIV infection, hepatitis B and C risk groups: results of serological screening. Med Parazitol (Mosk) 2013;(2):13-7.

52. Mendonça LR, Figueiredo CA, Esquivel R, Fiaccone RL, Pontes-deCarvalho L, Cooper P, et al. Seroprevalence and risk factors for Toxocara infection in children from an urban large setting in Northeast Brazil. Acta Trop 2013;128:90-5.

53. Archelli S, Santillan GI, Fonrouge R, Céspedes G, Burgos L, Radman N. Toxocariasis: seroprevalence in abandoned-institutionalized children and infants. Rev Argent Microbiol 2014;46:3-6.

54. Marchioro AA, Colli CM, Ferreira ÉC, Viol BM, Araújo SM, FalavignaGuilherme AL. Risk factors associated with toxoplasmosis and toxocariasis in populations of children from nine cities in southern Brazil. J Helminthol 2015;89:428-32.

55. Martínez M, García H, Figuera L, González V, Lamas F, López K, et al. Seroprevalence and risk factors of toxocariasis in preschool children in Aragua state, Venezuela. Trans R Soc Trop Med Hyg 2015;109:579-88.

56. Cortés NN, Núñez CR, Guiliana BG, García PA, Cárdenas RH. Presence of anti-Toxocara canis antibodies and risk factors in children from the Amecameca and Chalco regions of México. BMC Pediatr 2015;15:65.

57. Gabrielli S, Tasić-Otašević S, Ignjatović A, Fraulo M, Trenkić-Božinović $\mathrm{M}$, Momčilović S, et al. Seroprevalence and risk factors for Toxocara canis infection in Serbia during 2015. Foodborne Pathog Dis 2017;14:43-9.

58. Sowemimo OA, Lee YL, Asaolu SO, Chuang TW, Akinwale OP, Badejoko $\mathrm{BO}$, et al. Seroepidemiological study and associated risk factors of Toxocara canis infection among preschool children in Osun State, Nigeria. Acta Trop 2017;173:85-9.

59. Fialho PMM, Correa CRS, Lescano SZ. Asthma and Seroconversion from Toxocara spp. infection: which comes first? Biomed Res Int 2018; 2018:4280792.

How to cite this article: Abedi B, Akbari M, KkodaShenas S, Tabibzadeh A, Abedi A, Ghasemikhah R, et al. The global prevalence of Toxocara spp. in pediatrics: a systematic review and meta-analysis. Clin Exp Pediatr 2021;64:575-81. https:// doi.org/10.3345/cep.2020.01039 